\title{
Environmental Threats of Ancient Pb Mining and Metallurgical Activities in the Linares Mining District (Southern Spain) ${ }^{\dagger}$
}

\author{
Carlos Boente 1,* , Carlos Sierra ${ }^{2}$, Julián Martínez ${ }^{3}$, Eduardo Rodríguez-Valdés ${ }^{1}$, Elías Afif ${ }^{4}$, \\ Javier Rey ${ }^{3}$ and José Luis Rodríguez Gallego ${ }^{1, *}$ \\ 1 INDUROT and Environmental Technology, Biotechnology and Geochemistry Group, \\ University of Oviedo, C/Gonzalo Gutiérrez Quirós s/n, 33600 Mieres, Spain; rodriguezreduardo@uniovi.es \\ 2 Department of Mining, Topography and Structural Engineering, University of León, \\ Av/ Silverio Fernández Tirador, 24007 León, Spain; sierrafernandezcarlos@gmail.com \\ 3 Polytechnic School of Linares, Universidad de Jaén, 23700 Linares, Spain; jmartine@ujaen.es (J.M.); \\ jrey@ujaen.es (J.R.) \\ 4 Department of Biology of Organisms and Systems, University of Oviedo, C/Gonzalo Gutiérrez Quirós s/n, \\ 33600 Mieres, Spain; elias@uniovi.es \\ * Correspondence: boentecarlos@uniovi.es (C.B.); jgallego@uniovi.es (J.L.R.G.); Tel. +34-985-45-82-03 (C.B.) \\ + Presented at the 2nd International Research Conference on Sustainable Energy, Engineering, Materials and \\ Environment (IRCSEEME), Mieres, Spain, 25-27 July 2018.
}

Published: 6 November 2018

\begin{abstract}
Former industrial sites are now dedicated to other land uses in the Linares mining district. Here we selected five residential/farming areas (squares of $1 \mathrm{~km}^{2}$ each) and sought to evaluate the levels of contamination by Potentially Toxic Elements (PTEs) of the soils, and also to offer an insight into the threat these pollutants may pose to human health or the environment by means of risk assessment. High concentrations especially of $\mathrm{Pb}$, and also of $\mathrm{As}, \mathrm{Cd}, \mathrm{Cu}$ and $\mathrm{Zn}$ were found in quantities that are considerably bioavailable. Moreover, risk assessment revealed unacceptable concentrations for $\mathrm{Pb}$ and $\mathrm{As}$ in all the areas as well as for $\mathrm{Cd}$ and $\mathrm{Cu}$ in some squares.
\end{abstract}

Keywords: soil pollution; metal mining area; trace elements; risk assessment; remediation

\section{Introduction}

The accumulation of chemicals in former mining and metallurgy sites can damage the quality of soils in the nearby areas, leading to undesirable effects risks for living organisms. This scenario is particularly relevant when mechanical weathering like deflation, erosion, and thermal stress act coupled to active chemical weathering, hydration, or hydrolysis of the silicates and carbonates, thus releasing pollutants into the environment [1].

Risk assessment takes into consideration both hazard and exposure, and therefore the bioavailability of compounds. It involves procedures for estimating the probability of occurrence of any given magnitude of adverse health effects over a certain period of time [2]. In this context, baseline human health risk assessment (BHRA) is the analysis of the potential adverse health effects caused by exposure to hazardous substances released from a site in the absence of any measures to control or mitigate their mobility (i.e., under an assumption of no action) [2]. The BHRA model was developed following the Risk Assessment Guidance for Superfund [2] since it is considered that simple site-specific risk assessment offers a reasonable compromise between effort and sitespecificity [3]. 
It is necessary to remediate soils for which concentration of PTEs suppose a risk for human health or environment. Most strategies are based on the isolation and treatment of the polluted soil; these approaches include the following processes [4]: (1) thermal; (2) chemical, by dissolving contaminants in soil particles in washing water, and then treating the water with solidifying agents to produce relatively inert cement-like material; (3) physical, by electrokinetic procedures that remove trace elements by applying an electric current, or by concentrating contaminants into a smaller volume of soil through physical separation processes, thereby reducing the volume of the contaminated material; and (4) biological procedures, which use living organisms for remedial purposes, as is the case of phytoremediation. In all of these approaches it is important to assess soil composition and the mobility, availability and distribution of the pollutants.

All things together, here we sought to:

- Assess the levels of contamination of the areas in question (five sites within Linares mining district).

- Offer an insight into the threat these pollutants may pose to human health and the environment in the study site.

- $\quad$ Discuss the selection of appropriate soil remediation technologies.

\section{Materials and Methods}

\subsection{Study Area}

The study area is located in the Linares mining district (Spain). In this area, there were selected five areas (Figure 1):

- La Garza (square 12): Soil well developed and cereals are cultivated. There are signs of former mining.

- La Cruz Foundry (24): Old facilities of the mining district. Vegetation is not present in this square.

- $\quad$ San Genaro mine outskirts (25): Old shaft, now abandoned. Tree plantations are promoted here.

- Arrayanes (38): It is located in the vicinity of a former mineral processing plant.

- Pozo Ancho's mine shaft (51): This area contains a vast amount of mine waste.
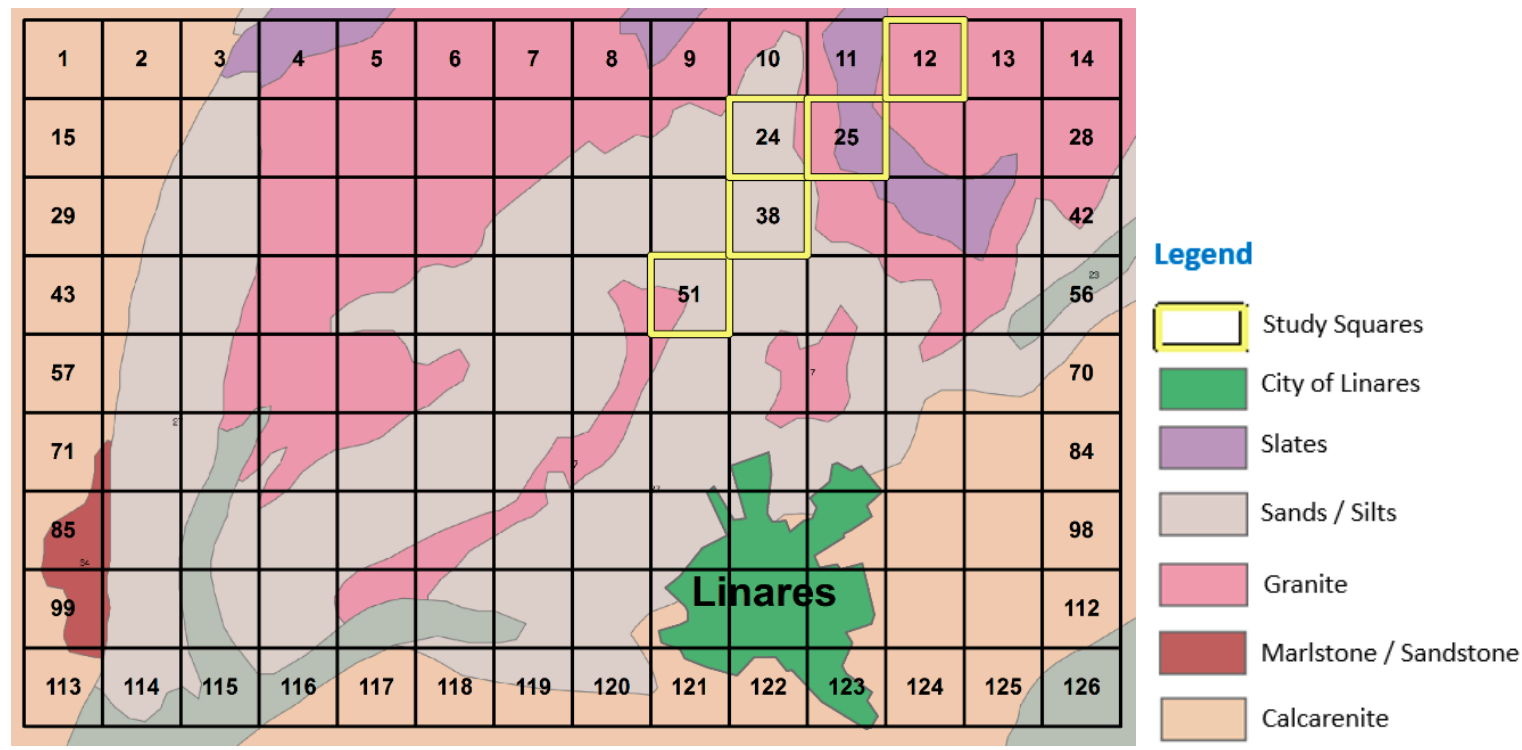

Figure 1. Situation map of the Linares mining district with outcropping lithology and studied grid squares ( $1 \mathrm{~km}^{2}$ each). 


\subsection{Pollution Study}

Composite samples of about $50 \mathrm{~kg}$ were taken from 0-35 $\mathrm{cm}$ depth for each square. Being airdried and sieved $(2 \mathrm{~mm})$, before the chemical analyses that they were subjected:

- $\quad \mathrm{pH} \&$ Electrical conductivity by glass electrode in soil-water suspension.

- Particle-size distribution by the pipette method.

- Element concentration of $\mathrm{As}, \mathrm{Cd}, \mathrm{Cu}, \mathrm{Pb}$ and $\mathrm{Zn}$ by ICP-OES

- Sequential Extraction by BCR procedure. Four fractions obtained (Carbonate-bound, Fe-Mn oxide-bound, organic matter-bound and residual fraction). First two are the bioavailable term.

- Other soil parameters (\% OM, ECEC, mineral phases, etc...).

This allowed to provide a properly edaphic and chemical characterization of the soil. Afterwards, a Risk assessment by means of the Baseline Human Health Risk Assessment (BHRA) for on-sire receptors was conducted. It was performed for $\mathrm{As}, \mathrm{Cd}, \mathrm{Cu}, \mathrm{Pb}$ and $\mathrm{Zn}$ taken from exchangeable fractions from BCR. The analysis combines toxicity and exposure assessments and it considers carcinogenic and non-carcinogenic risks following the ISIS guidelines.

\section{Results and Discussion}

\subsection{Analytical Results}

Accordingly, the soils in the study area were neutral (square 24, $\mathrm{pH}=6.87$ ), slightly alkaline (sample 12, 25 and 51, $\mathrm{pH}=7.46,7.5$ and 7.97 respectively) or medium alkaline (sample 38, $\mathrm{pH}=8.17$ ). The upper horizon showed low organic matter content $(<1.5 \%)$. Electrical conductivity was low in samples 12, 25 and $51\left(\mathrm{EC}<0.15 \mathrm{dS} \mathrm{m}^{-1}\right)$, while the samples 24 and 38 had higher electrical conductivity ( $\mathrm{EC}=1.33$ and $0.91 \mathrm{dS} \mathrm{m}^{-1}$, respectively), indicating salinization issues. Salinity can have a major effect on soil structure. In this regard, soil structure, or the arrangement of soil particles, greatly affects permeability and infiltration. Soil EC can serve as a proxy for soil chemical properties such as organic matter, clay content, and cation exchange capacity [5]. Moreover, element concentrations and bioavailability results from BCR extraction are summarized in Table 1.

Table 1. Element concentration for each square, expressed in ppm. Values in parenthesis represents bioavailability, corresponding to the first two of fractions of the BCR procedure.

\begin{tabular}{cccccc}
\hline Square & $\mathbf{A s}$ & $\mathbf{C d}$ & $\mathbf{C u}$ & $\mathbf{P b}$ & $\mathbf{Z n}$ \\
\hline $\mathbf{1 2}$ & $18.5(1.2 \%)$ & $0.7(<\mathrm{DL})$ & $67(20.6 \%)$ & $5158(66.1 \%)$ & $33(22.6 \%)$ \\
$\mathbf{2 4}$ & $139.5(2 \%)$ & $18.7(58.7 \%)$ & $357(24.1 \%)$ & $4244(46.0 \%)$ & $694(51.2 \%)$ \\
$\mathbf{2 5}$ & $84.4(0 \%)$ & $3.4(51.2 \%)$ & $381(18.5 \%)$ & $35899(40.8 \%)$ & $473(15.8 \%)$ \\
$\mathbf{3 8}$ & $134.5(19.2 \%)$ & $2.8(21.2 \%)$ & $587(0 \%)$ & $9872(35.6 \%)$ & $7468(44.9 \%)$ \\
$\mathbf{5 1}$ & $41.6(0.4 \%)$ & $1.8(<\mathrm{DL})$ & $722(12.5 \%)$ & $9870(35.5 \%)$ & $143(13.9 \%)$ \\
\hline
\end{tabular}

Regarding element concentrations, $\mathrm{Pb}$ concentrations are very high in all the areas, reaching values considered toxic to plants. However, Square 12 is the one that presents low concentrations for the remaining elements, being only affected by these PTEs. Intervention values are surpassed in almost all cases and at least one time for each element analyzed. This means that a soil remediation is required, especially for the high levels of $\mathrm{Pb}$.

This proposal is reinforced by glancing at the sequential extraction results. The bioavailable fraction corresponds to the $\mathrm{F} 1$ of the BCR (carbonate-bound). In this respect, equilibrium for metals of this fraction is even possible with the aqueous phase. Therefore they present high relative mobility, thus being easily bioavailable. In general terms, $\mathrm{Cd}, \mathrm{Cu}, \mathrm{Pb}$ and $\mathrm{Zn}$, as opposed to As, were highly available as they were present in the carbonate fraction. The high concentration of these elements in this fraction may be indicative of anthropogenic contamination, as well as recent pollution. 


\subsection{Risk Assessment Results}

Four exposure pathways were considered for this land use, as stated by national legislation; i.e., oral ingestion (dust and soil particles), dermal contact, inhalation (vapor and soil particles), and food consumption (cultivation in polluted soils). For the latter, the soil concentrations of trace elements used for the calculation correspond to the exchangeable fractions from the BCR sequential extraction procedure.

In this regard, the assessment of natural-soil land use introduces As, as in other scenarios, as the element with the largest contribution to overall risk because of its carcinogenic nature. This happens by the fact that it is the only carcinogenic element and it has more restrictive levels. Nevertheless, $\mathrm{Cu}$ and $\mathrm{Cd}$ also exceeded the maximum accepted risk quotient $(\mathrm{HQ}=1)$ for squares 24,25 and $51 . \mathrm{Pb}$ concentrations in the grids were so high that specific risk assessment showed an unacceptable risk for human health. Inorganic $\mathrm{Pb}$ risk assessment was based on predicting PbBs for current and potential future populations in relation to compound exposure. All grids showed $\mathrm{PbBs}$ exceeding the limit of $5 \mu \mathrm{g} / \mathrm{dL}$ for both models.

\section{Conclusions}

The soil of the Linares district present anomalous concentrations of $\mathrm{As}, \mathrm{Cd}, \mathrm{Cu}, \mathrm{Pb}$ and $\mathrm{Zn}$, exceeding admisible limits of $\mathrm{Pb}$ and $\mathrm{As}$ in all the study sites. This is more worrying since a significant proportion of the PTEs (especially $\mathrm{Pb}$ ) are present in bioavailable forms. This led the risk assessment to unveil a threat to human health; Squares 24,25 and 51 are priority objectives for soil remediation.

We consider that phyisical separation might be a proper remediation given that most of the pollutants are concentrated in the fine grain size fraction $(<63 \mu \mathrm{m})$, mainly in squares $12,38,51$. We suggest gravity and even magnetic separation as complementary procedures given the nature of the minerals and waste found. A second possibility is phytorremediation (phytoextraction or phytostabilization), as the available fractions of soil pollutants are significant.

Author Contributions: C.S., E.A., J.M. and J.L.R.G. conceived and designed the experiments; C.S. performed the experiments and made the interpretation of the results; E.R.-V. carried out the risk assessment; J.R. and C.B. designed tables and figures; C.B. wrote the paper.

Acknowledgments: Carlos Boente obtained a grant from the "Formación del Profesorado Universitario" program, financed by the "Ministerio de Educación, Cultura y Deporte de España".

Conflicts of Interest: The authors declare no conflict of interest.

\section{References}

1. Gallego, J.R.; Esquinas, N.; Rodríguez-Valdés, E.; Menéndez-Aguado, J.M.; Sierra, C. Comprehensive waste characterization and organic pollution co-occurrence in a $\mathrm{Hg}$ and As mining and metallurgy brownfield. J. Hazard. Mater. 2015, 300, 561-571.

2. United States Environmental Protection, Agency. Risk Assessment Guidance for Superfund, Vol. I. Human Health Evaluation Manual (Part A); EPA/540/1-89/002; Office of Research and Development: Washington, DC, USA, 1998.

3. United States Environmental Protection, Agency. Supplemental Guidance for Developing Soil Screening Levels for Superfund Sites; OSWER Directive 9355.4-24; Office of Solid Waste and Emergency Response: Washington, DC, USA, 2002.

4. Yao, Z.; Li, J.; Xie, H.; Yu, C.; Review on remediation technologies of soil contaminated by heavy metals. Procedia Environ. Sci. 2012, 16, 722-729.

5. Hanson, B.R.; Grattan, S.R.; Fulton, A. Agricultural Salinity and Drainage; University of California, Division of Agriculture and Natural Resources Publication: Oakland, CA, USA, 2006. 